\title{
Factors that Affect Nonmarket Fruit and Vegetable Receptions: Analyses of Two Cross-Sectional Surveys in Gunma, Japan
}

\author{
Daisuke Machida ${ }^{1, *}$ and Tohru Yoshida ${ }^{2}$ \\ 1 Department of Health and Nutrition, Faculty of Health and Welfare, \\ Takasaki University of Health and Welfare, Takasaki 370-0033, Gunma, Japan \\ 2 Department of Human Welfare, Faculty of Human Life, Jumonji University, Niiza 352-8510, Saitama, Japan; \\ t-yosida@jumonji-u.ac.jp \\ * Correspondence: machida-d@takasaki-u.ac.jp; Tel.: +81-27-352-1290
}

Received: 9 September 2019; Accepted: 18 October 2019; Published: 23 October 2019

check for updates

\begin{abstract}
In this study, we identified the factors that affect the frequency of receiving nonmarket fruit and vegetables (FV). For Survey 1, we conducted a cross-sectional survey using a self-administered questionnaire for men aged 50-74 living in city (A) in Gunma, Japan. Participants were asked questions on FV receiving frequency, FV gardening, social cohesion (4-20 points), and basic characteristics. For Survey 2, a similar survey was conducted for residents aged 20-74 in three areas in city (B) in Gunma, but we included more variables. Ordinal logistic regression models were used for the analysis. In Survey 1, the responses of 243 participants were analyzed. The results showed that the FV receiving frequency was positively associated with non-gardeners and social cohesion. In Survey 2, the responses of 791 participants were analyzed. Vegetable receiving frequency was positively associated with rural and suburban areas, family structure, employment status, and non-farmers. The relationship between receiving frequency and social cohesion was similar to that found in Survey 1. In conclusion, in areas with flourishing FV cultivation, it seems to be easy to obtain FV through the social networks of reception, even for individuals who are not cultivating FV themselves.
\end{abstract}

Keywords: fruit and vegetable intake; fruit and vegetable receiving; locally-grown products; local food system; nonmarket food; social cohesion

\section{Introduction}

A growing interest in alternative food networks (AFNs) has become evident [1]. This may be due to the increasing criticism of the current food system regarding negative impacts on human wellbeing and sustainability [1,2]. Forssell et al. [1] states that AFNs have the following five characteristics: "Participants' non-conventional values and goals"; "increased requirements for products and production"; "reduced distance between producers and consumers"; "new forms of market governance"; and "strong relationships, exemplified by notions of trust and social embeddedness". AFNs include practices such as community supported agriculture, farmers' markets, organic farms, cooperatives, solidarity purchasing groups, farm shops, urban agriculture, box scheme, and community gardens [2]. The distribution of nonmarket food (home grown foods and foods received from neighbors and/or relatives [3-7]) can be considered one aspect of AFNs that is related to the previously described characteristics [1]. Further, studies on urban gardening, home gardening, and community gardening can be seen in other works [8-11]. In a systematic review, both the consuming of crops grown in the gardens themselves and the sharing of crops with community members were observed [9]. 
In Japan, particularly rural areas, the distribution of nonmarket food is thriving, and the distribution of nonmarket food has an impact on Japanese people's dietary habits [3-7]. In the Noto Peninsula (a traditional Japanese rural setting called Satoyama [3]), there was a greater diversity in and a higher ratio of daily meal products produced at home compared to other areas of Japan [4]. Moreover, the variety and quantity of nonmarket foods also differ depending on the areas within the Noto Peninsula [3]. In addition, if people have more food sharing partners, greater diversity and quantities may be obtained from nonmarket food sources [3]. On Hachijo Island, nonmarket potatoes, vegetables, and fish are widely available [5]. Furthermore, nonmarket foods account for approximately $25 \%$ of the production price basis and around $17 \%$ of the caloric basis within food consumption as a whole [5]. Approximately half of all food consumed was from nonmarket sources between the spring and autumn seasons [6]. In addition, a nationwide internet survey reported that there were no significant differences in the ratio of access to nonmarket foods because of the agricultural area classification, and there was a significant relationship between land use types and obtaining amounts and varieties of nonmarket food [4,7]. Nonmarket food distribution largely consists of locally harvested crops that are suited to the local climate and carry a relatively low environmental burden [12]. Nonmarket food is also important for survival in the event of a disaster [13]. All these aspects align with the following sustainable development goal:

“2.4. By 2030, ensure sustainable food production systems and implement resilient agricultural practices that increase productivity and production, that help maintain ecosystems, that strengthen capacity for adaptation to climate change, extreme weather, drought, flooding, and other disasters and that progressively improve land and soil quality." [14]

Increased fruit and vegetable (FV) intake have reduced mortality as well as the risk of cardiovascular disease $[15,16]$. From a health promotion perspective, it is important that the distribution of nonmarket FV contributes to overall increases in FV intake. Among several studies that confirm the relationship between nonmarket FV distribution and FV intake, a positive relationship was widely observed between gardening or food cultivation and FV intake in Japan [17-22]. This relationship has been globally reported and is generally positive and consistent [8-11]. It has also enabled a deeper understanding of the characteristics and motivations of those engaged in FV gardening [20,23-25]. Additionally, there are several reports on the association between FV receiving and FV intake [17-19]. In rural Japanese areas, the higher intake of the receiving vegetable, the higher the total vegetable intake [17]. There is an interaction between vegetable cultivation and vegetable receiving frequency that affects vegetable intake [18]. Furthermore, a positive relationship exists between vegetable cultivation and vegetable intake, as well as a positive relationship between vegetable receiving and vegetable intake, even if individuals or their families do not grow vegetables themselves [19]. However, there are no empirical studies on factors affecting FV receiving frequency. If FV receiving is positively related to FV intake, understanding the underlying factors may lead to a better interpretation of these ecosystems, and it may contribute to sustainable health and the promotion of associated food systems [26]. In other words, it may help increase FV intake and promote health in a socially, economically, and environmentally sustainable manner.

In this paper, we seek to identify factors that affect FV receiving frequency. This study was a secondary analysis of two cross-sectional data surveys $[17,21,27]$. Thus, the selection of participants was not optimally designed for the present purpose. However, additional analyses may offer some useful findings for future studies.

\section{Materials and Methods}

\subsection{Survey 1}

\subsubsection{Participants and Methods}

The participants in this study were men aged 50-74 years living in three census tracts in a city in Gunma Prefecture, Japan. The primary purpose of this survey was to identify the health effects 
of community gardening [21]. Consequently, only the population of men aged 50 or over who had several motives to use community gardening from the previous research in Japan was included in the study [24]. The city in question is located in the south of Gunma, covers $139.4 \mathrm{~km}^{2}$, and has a population of approximately 210,000 residents. We used a multiple frame sampling approach to refer to previous studies on community gardening $[28,29]$. The first framework involved the participants of community gardens in the three census tracts. This area was a suburban setting with farmland within the residential areas. An explanatory document and a self-administered questionnaire were distributed directly by the staff of the community garden management organization (25 April 2014). The second framework was for residents of the three census tracts. Each household was sent an explanatory document and a self-administered questionnaire through Delivery Area Designated Mail (Japan Post Co., Ltd. Tokyo, Japan; 25 April 2015). This service allows mail to be delivered to all households in a designated area while keeping the participants' specific addresses private. The explanatory document requested a response from men aged 50-74 years. Moreover, when there were two or more men aged 50-74 in a household, we asked that only one of them reply. To avoid the duplication of answers between the two sample frameworks, the explanatory document clearly stated that those answering the community garden questionnaires were not required to cooperate. The survey was conducted anonymously and consent was obtained if the questionnaire was completed.

By 31 May 2015, 253 completed questionnaires had been collected. Approximately 200 were distributed to the community gardeners with 25 replies. For the residents, 3397 questionnaires were delivered to the households in the three towns, with 228 responses. Of these, 10 with missing values were excluded, resulting in 243 questionnaires for the analysis. The response rate was not calculated because the correct number of participants could not be determined in any sample framework. The survey was approved by the Gunma University ethical review board for epidemiological research (submission no. 26-58; 4 February 2015).

\subsubsection{Survey Instrument}

To determine whether the men were receiving FV from people in their social network, participants were asked the following question: "How often do you obtain fruits and vegetables from relatives or neighbors?" The answers were ranked as follows: 1 (never), 2 (rarely), 3 (sometimes), and 4 (often). This item was set with reference to a previous study [30].

To determine whether or not a participant performed FV cultivation or gardening, they were asked to provide an answer of "yes" or "no" for the following question: "Do you grow fruits and vegetables?" In this survey, gardeners and farmers were combined into the "gardener" group, and those who answered no were classified as the "non-gardener" group.

Social cohesion was scaled using four items from neighborhood scales as developed by Mujahid et al. [31], which have since been adapted for Japanese populations [32]. Participants were asked to rate four statements on a scale from 1 (strongly disagree) to 5 (strongly agree). These were as follows: "People around here are willing to help their neighbors"; "people in my neighborhood generally get along with one another"; "people in my neighborhood can be trusted"; and "people in my neighborhood share the same values". We created a social cohesion index by adding the scores for these four items (Cronbach $\alpha=0.851$ ).

Furthermore, participants were asked to provide information regarding basic characteristics such as their age, educational background, and employment status.

\subsection{Survey 2}

\subsubsection{Participants and Methods}

We used the same dataset as that described in previous articles. The primary purposes of this survey were to estimate regional differences in vegetable intake and the impact of locally grown vegetable acquisition upon vegetable intake $[17,27]$. The participants in this cross-sectional 
study were residents (both of men and women) aged 20-74 years who were living in three areas of city (B) within Gunma, Japan. This city is located in the center of Gunma, covers $459.2 \mathrm{~km}^{2}$, and has a population of approximately 370,000 residents. Within this city, we identified three geographic regions, each with a population of about 1000 people aged 20-74 years, that could be classified as rural, suburban, and urban [27]. Additionally, in the agricultural area classification system developed by the Japanese Ministry of Agriculture, Forestry and Fisheries, these areas are considered "mountainous agricultural area(s)", "flat agricultural area(s)" and "urbanized area(s)", respectively $[7,33]$. Furthermore, the previous study indicated that there were more vegetable growers (constituted by both farmers and gardeners) in the rural and the suburban areas than in the urban area [27].

We collected the survey data during September and October 2016 using a self-administered, anonymous questionnaire. We mailed the questionnaire to 2260 households through Delivery Area Designated Mail (Japan Post Co., Ltd.; Tokyo, Japan; 12 September 2016). We mailed two sets of questionnaires to all households in the three areas. An explanatory letter and a stamped, self-addressed return envelope were enclosed with the questionnaire. The explanatory letter stated the following: (1) two residents should reply if there were three or more residents aged 20-74 years in the household, and (2) ethical matters, such as arbitrariness and anonymity, would be handled securely. In addition, we numbered each questionnaire so that we could identify from which of the three geographic areas each response was received. A total of 873 residents from 586 households responded (representing a $25.9 \%$ household response rate), of which 82 responses with missing values were excluded. Therefore, we used responses from 791 participants for the analyses. This survey was approved by the Gunma University Ethical Review Board for Medical Research Involving Human Subjects (submission no. 160074, approved on 16 August 2016).

\subsubsection{Survey Instrument}

The vegetable receiving frequency and social cohesion (Cronbach $\alpha=0.892)$ were measured with the same tool as Survey 1.

To understand the self-perceptions about vegetable growing, we asked participants the following question: "Do you or members of your household grow vegetables?" Participants who answered yes were further asked whether they grew the vegetables as farmers, home gardeners, community gardeners, or other gardeners. From these responses, we classified those who answered farmer as "farmer"; those who answered home gardener, community gardener, or other gardener as "gardener"; and those who answered no as "non-grower".

Further, we assessed subjective difficulty in food-store access by using a single item from a previous study, which asked the participants about their subjective difficulty with food-store access in one of four categories: "very difficult", "difficult", "easy" and "very easy" [30]. The respondents' economic circumstances were assessed by using a single item that asked them to indicate their economic situation in five categories: "very poor", "poor", "fair", "good" and "very good". This item was confirmed as having a positive relationship with household income in a previous study [34]. We assessed health attitudes using a single item: "Are you usually health-conscious?" Participants answered in one of four categories: "not at all", "little", "occasionally" and "often, or all the time". Subjective difficulty with food-store access (difficult and easy) and health attitude (low or not at all/little) and high (occasionally/often/all the time) were divided into two categories, and economic circumstances were divided into three categories because there was an intermediate choice (poor, fair, and good). In addition, the participants were asked about basic characteristics, such as their sex, age, family structure, educational background, and employment status.

\subsection{Analyses}

First, we described participants' characteristics according to the FV receiving frequencies obtained from Survey 1 and analyzed the different responses according to FV receiving frequency using a 
one-way ANOVA test for social cohesion and chi-square tests for all the other variables. Subsequently, we identified the factors related to the FV receiving frequencies of Survey 1 using an ordinal logistic regression model. The FV receiving frequency was used as a dependent variable. All other variables were used as independent variables, and we computed a partial regression coefficient $(\beta)$ and a $95 \%$ confidence interval $(95 \% \mathrm{CI})$.

We conducted a similar analysis for Survey 2. In the ordinal regression model, vegetable receiving frequency was used as the dependent variable, and all other variables were used as independent variables. In addition, we attempted a similar analysis for only non-gardeners using the data obtained from Survey 2. This is because previous research has suggested that the relationship between vegetable receiving frequency and vegetable intake is particularly strong among non-gardeners $[17,18]$.

A two-tailed $p$-value that was less than 0.05 was considered statistically significant. All analyses were performed using the statistical software package IBM SPSS Statistics, Version 23 (Armonk, NY, USA).

\section{Results}

\subsection{Survey 1}

The characteristics of Survey 1 participants are described in Table A1. FV gardening status $(p=0.002)$ and social cohesion $(p=0.003)$ were significantly related with the FV receiving frequency.

An examination of factors related to the FV receiving frequency from Survey 1 (Table 1) indicated significant relationships with non-gardeners $(\beta=0.617, p=0.027)$ and social cohesion $(\beta=0.198$, $p<0.001)$.

Table 1. Relationship with FV receiving frequency (Survey 1).

\begin{tabular}{ccc}
\hline & $\beta(\mathbf{9 5} \% \mathbf{C I})$ & $p$-Value \\
\hline Age: $\geq 60$ (Ref: $<60)$ & $0.309(-0.374-0.992)$ & 0.375 \\
\hline Education: $>$ high school (Ref. $\leq$ high school) & $-0.515(-1.055-0.026)$ & 0.062 \\
\hline Employed (Ref. unemployed or retired) & $0.225(-0.335-0.785)$ & 0.431 \\
\hline Non-gardener (Ref. FV gardener) & $0.617(0.071-1.163)$ & 0.027 \\
\hline Social Cohesion $(4-20)$ & $0.198(0.097-0.299)$ & $<0.001$ \\
\hline
\end{tabular}

Ordinal logistic regression models; $N=243$; likelihood-ratio test: $p<0.001$; Dependent variable: FV receiving frequency $($ Never $=1$ to Often $=4$ ); FV: fruit and vegetable. $\beta$ : partial regression coefficient; $95 \%$ CI: $95 \%$ confidence interval.

\subsection{Survey 2}

The characteristics of Survey 2 participants are described in Table A2. There were significant differences in area $(p<0.001)$, age $(p<0.001)$, family structure $(p<0.001)$, educational background $(p=0.008)$, and social cohesion $(p=0.003)$ in comparison to vegetable receiving frequency. The non-gardeners' characteristics are described in Table A3. Similar trends with area $(p<0.001)$, family structure $(p<0.001)$, and social cohesion $(p=0.003)$ were evident. In addition, significant differences in sex $(p=0.016)$ and employment status $(p=0.013)$ were indicated. However, age $(p=0.142)$ and educational background $(p=0.250)$ had no significant difference when compared to vegetable receiving frequency.

An examination of factors related to the FV receiving frequency of Survey 2 (Table 2) indicated significant relationships with area (suburban: $\beta=0.437, p=0.014$; rural: $\beta=1.142, p<0.001$ ), living with two or more household members $(\beta=0.831, p<0.001)$, being employed $(\beta=0.405$, $p=0.011$ ), vegetable growing (gardener: $\beta=0.688, p=0.001$; non-grower: $\beta=0.699, p=0.002$ ), and social cohesion $(\beta=0.104, p<0.001)$. Among non-growers, significant relationships were also shown with area (suburban: $\beta=0.599, p=0.009$; rural: $\beta=1.583, p<0.001$ ), living with two or more 
household members ( $\beta=0.958, p<0.001)$, and social cohesion $(\beta=0.140, p<0.001)$, but employment status was not significant $(\beta=0.303, p=0.203)$.

Table 2. Relationship with vegetable receiving frequency (Survey 2).

\begin{tabular}{|c|c|c|c|c|}
\hline & \multicolumn{2}{|c|}{ Whole Participants * } & \multicolumn{2}{|c|}{ Among Non-Grower ** } \\
\hline & $\beta(95 \% \mathrm{CI})$ & $p$-Value & $\beta(95 \% \mathrm{CI})$ & $p$-Value \\
\hline \multicolumn{5}{|l|}{ Area (Ref: urban) } \\
\hline suburban & $0.437(0.090-0.783)$ & 0.014 & $0.599(0.150-1.048)$ & 0.009 \\
\hline rural & $1.142(0.742-1.542)$ & $<0.001$ & $1.583(0.993-2.172)$ & $<0.001$ \\
\hline Sex: men (Ref: women) & $-0.254(-0.522-0.013)$ & 0.062 & $-0.244(-0.639-0.152)$ & 0.227 \\
\hline Age: $\geq 60$ (Ref: $<60$ ) & $-0.329(-0.660-0.001)$ & 0.051 & $-0.262(-0.768-0.244)$ & 0.311 \\
\hline $\begin{array}{l}\text { Living } 2 \text { or more members } \\
\text { (Ref: living alone) }\end{array}$ & $0.831(0.424-1.238)$ & $<0.001$ & $0.958(0.436-1.479)$ & $<0.001$ \\
\hline $\begin{array}{l}\text { Education: >high school } \\
\text { (Ref: } \leq \text { High school) }\end{array}$ & $0.206(-0.088-0.500)$ & 0.169 & $-0.286(-0.722-0.150)$ & 0.199 \\
\hline $\begin{array}{c}\text { Employed } \\
\text { (Ref: unemployed/retired) }\end{array}$ & $0.405(0.091-0.719)$ & 0.011 & $0.303(-0.164-0.769)$ & 0.203 \\
\hline \multicolumn{5}{|l|}{ Economic circumstances (Ref: poor) } \\
\hline Fair & $-0.004(-0.356-0.349)$ & 0.984 & $0.163(-0.347-0.673)$ & 0.532 \\
\hline Good & $0.003(-0.348-0.355)$ & 0.985 & $0.425(-0.083-0.932)$ & 0.101 \\
\hline Health Attitude: high (Ref: low) & $-0.019(-0.315-0.277)$ & 0.900 & $-0.171(-0.586-0.244)$ & 0.420 \\
\hline $\begin{array}{l}\text { Food-store Access: easy } \\
\text { (Ref: difficult) }\end{array}$ & $-0.167(-0.470-0.135)$ & 0.279 & $-0.024(-0.449-0.401)$ & 0.910 \\
\hline \multicolumn{5}{|l|}{ Vegetable Growing (Ref. farmer) } \\
\hline Gardener & $0.688(0.059-1.107)$ & 0.001 & & \\
\hline Non-grower & $0.699(0.270-1.147)$ & 0.002 & & \\
\hline Social Cohesion (4-20) & $0.104(0.251-0.149)$ & $<0.001$ & $0.140(0.077-0.203)$ & $<0.001$ \\
\hline
\end{tabular}

\section{Discussion}

In this study, we identified the factors affecting the FV receiving frequency. In previous studies, the characteristics and motivations of those engaged in FV gardening [20,23-25] were reported. Furthermore, in the context of obtaining locally-grown produce, the motivations and characteristics were reported by using farmers' markets [35-38]. However, we have not managed to uncover other studies that reveal factors related to FV receiving. FV gardening and purchasing at farmers' markets are active behaviors. Conversely, receiving is a relatively passive behavior. Therefore, we reasonably inferred that these factors are considerably different. Hence, identifying the factors related to FV receiving in this study has important implications. In particular, we were able to generate data that, when analyzed, will be of great use in developing a scheme to increase accessibility among those who do not have an active FV intake. In turn, this could lead to an increased FV intake and may contribute to the overall health promotion of those involved. Additionally, it has a low environmental impact [12] and can be said to constitute a form of emergency resilience [13]. Thus, interpreting this result contributes to achieving sustainable development goals [14]. Further studies about the distribution of nonmarket FV are required, particularly for FV receiving as a passive behavior in the context of AFNs. The details of the factors related to FV receiving are discussed below.

The vegetable receiving frequency in the rural and suburban areas was higher than in the urban area. Previous studies reported no significant difference in the ratio of access to nonmarket food because of the agricultural area classification $[4,7]$. However, there were significant relationships between land use types and the amounts and variety of nonmarket foods individuals consumed [7]. In the initial analysis of Survey 2, more people were growing vegetables in rural and suburban areas compared to urban areas [27]. Therefore, it is assumed that the differences in the vegetable receiving frequency 
according to area in Survey 2 reflected the land use types and not the agricultural area classification. Specifically, the more areas used for vegetable farmland, the higher the vegetable receiving rates from neighbors.

In addition, the relationship between social cohesion, family structure, working status, and FV or vegetable receiving frequency was confirmed. There may be broad social networks that are common to these backgrounds and consequently effective in this context [3]. Those who recognize social cohesion to a greater extent are likely to help each other. Further, the social network may spread in terms of significance in proportion to the number of families present. Moreover, people who are employed have a network with workplace colleagues. It is in keeping with commonsense interpretations that the $\mathrm{FV}$ receiving frequency increases if people who cultivate FV are in close proximity with each other and have a broad social network.

Furthermore, the FV receiving frequency of non-gardeners was high in Survey 1; in Survey 2 , gardeners and non-growers were more likely to receive vegetables than farmers. In addition, when analyzed with non-growers alone, the $\beta$ values of area, family structure, and social cohesion were greater than when analyzed as a whole. It is already well known that FV growing increases FV intake among growers and their family members [8-11,17-22]. Apart from this, the results suggest that FV growing increases FV intake not only among those growing FV (or their family members) but also among their neighbors. The initial analysis of Survey 2 confirms that vegetable growers give harvested vegetables to others at a rate of $15.3 \%$ among farmers and $17.3 \%$ among gardeners [17]. Generally, the amount of vegetables provided by farmers has a greater impact than that provided by gardeners since farmers' cultivation scales are far greater than those of gardeners.

Accordingly, we believe that $\mathrm{FV}$ are frequently given from farmers to non-farmer neighbors in areas where FV cultivation is high, and one of the factors promoting this exchange may be the social networks. Currently, in the rural areas of Japan, it seems that FV cultivation is flourishing and social cohesion is high in several cases. Consequently, increased FV intake among those who do not grow FV seems to be maintained through nonmarket food distribution. However, farmers are now on a downward trend, and the abandonment of cultivation areas is also increasing in Japan [39,40]. Moreover, the rural population in Japan has been decreasing, and social networks may also be decreasing according to decreasing numbers of local residents [41]. We should aim to rebuild this desirable set of Japanese rural conditions that is being slowly lost.

\section{Limitations}

This study included self-report data and has a probability of recall bias, i.e., respondents may overestimate or underestimate their specific condition. Generalization is difficult because it covers only the residents of two Japanese cities and the results may be significantly different in areas wherein vegetable cultivation is small, in Japan as well as in other countries (owing to differences in cultural contexts). Moreover, the possibility of sampling bias and response bias exist since it was performed by convenient sampling and the number of responses was not large. In the future, research designed to address these issues will be necessary. Finally, this was a cross-sectional study and further longitudinal studies are required to reveal the underlying causal relationships.

\section{Conclusions}

In this study, the factors affecting FV receiving frequency (such as rural or suburban area, living multiple members, non-gardeners or non-farmers, and social cohesion) were identified. Further, it was suggested that FV are frequently given from farmers to non-farmer neighbors in areas where FV cultivation is high and one of the factors promoting this may be social networks. We believe that these are sustainable food systems that promote the health of local residents, generate fewer environmental burdens, and serve as a form of resilience, particularly in emergency scenarios. Moreover, to maintain this food system, specific strategies are required to maintain land cultivation and social networks in 
the rural areas of Japan. Finally, future studies should consider the distribution of nonmarket food in the context of AFNs.

Author Contributions: Conceptualization, D.M. and T.Y.; methodology, D.M. and T.Y.; software, D.M.; formal analysis, D.M.; investigation, D.M. and T.Y.; writing-original draft preparation, D.M.; supervision, T.Y.; project administration, D.M.; funding acquisition, D.M.

Funding: This research was funded by the Nakatani Suzuyo Memorial Fund for Nutrition and Dietetics and JSPS KAKENHI (JP18K13037).

Acknowledgments: We would like to thank the participants in this study. The authors would like to thank Enago (www.enago.jp) for the English language review.

Conflicts of Interest: The authors declare no conflict of interest.

\section{Appendix A}

Table A1. Participants' characteristics according to FV receiving frequency (Survey 1).

\begin{tabular}{|c|c|c|c|c|c|c|c|c|c|c|c|}
\hline & \multicolumn{11}{|c|}{ FV Receiving Frequency } \\
\hline & \multicolumn{2}{|c|}{ Total } & \multicolumn{2}{|c|}{ Never } & \multicolumn{2}{|c|}{ Rarely } & \multicolumn{2}{|c|}{ Sometimes } & \multicolumn{2}{|c|}{ Often } & \multirow[b]{2}{*}{$p$-Value * } \\
\hline & $N$ & $\%$ & $n$ & $\%$ & $n$ & $\%$ & $n$ & $\%$ & $n$ & $\%$ & \\
\hline$N$ & 243 & 100.0 & 16 & 6.6 & 30 & 12.3 & 133 & 54.7 & 64 & 26.3 & \\
\hline \multicolumn{12}{|l|}{ Age } \\
\hline$<60$ & 53 & 21.8 & 5 & 31.3 & 4 & 13.3 & 33 & 24.8 & 11 & 17.2 & \multirow{2}{*}{0.307} \\
\hline$\geq 60$ & 190 & 78.2 & 11 & 68.7 & 26 & 86.7 & 100 & 75.2 & 53 & 82.8 & \\
\hline \multicolumn{12}{|l|}{ Educational background } \\
\hline$\leq$ High school & 148 & 60.9 & 9 & 56.2 & 17 & 56.7 & 80 & 60.2 & 42 & 65.6 & \multirow{2}{*}{0.801} \\
\hline >High school & 95 & 39.1 & 7 & 43.8 & 13 & 43.3 & 53 & 39.8 & 22 & 34.4 & \\
\hline \multicolumn{12}{|l|}{ Employment status } \\
\hline Unemployed/retired & 110 & 45.3 & 7 & 43.8 & 16 & 53.3 & 58 & 43.6 & 29 & 45.3 & \multirow{2}{*}{0.813} \\
\hline Employed & 133 & 54.7 & 9 & 56.2 & 14 & 46.7 & 75 & 56.4 & 35 & 54.7 & \\
\hline \multicolumn{12}{|l|}{ FV gardening } \\
\hline Non-gardener & 131 & 53.9 & 14 & 87.5 & 10 & 33.3 & 67 & 50.4 & 40 & 62.5 & \multirow{2}{*}{0.002} \\
\hline Gardener & 112 & 46.1 & 2 & 12.5 & 20 & 66.7 & 66 & 49.6 & 24 & 37.5 & \\
\hline \multirow[b]{2}{*}{ Social cohesion (4-20) } & Mean & SD & Mean & $\mathrm{SD}$ & Mean & $\mathrm{SD}$ & Mean & SD & Mean & SD & \\
\hline & 13.5 & 2.6 & 11.4 & 2.8 & 13.1 & 2.3 & 13.5 & 2.3 & 14.2 & 2.8 & 0.003 \\
\hline
\end{tabular}

* One-way ANOVA for social cohesion, and chi-square test for all the other valuables. FV: fruit and vegetable. SD: standard deviation. 
Table A2. Participants' characteristics according to vegetable receiving frequency (Survey 2).

\begin{tabular}{|c|c|c|c|c|c|c|c|c|c|c|c|}
\hline & \multicolumn{11}{|c|}{ Vegetable Receiving Frequency } \\
\hline & \multicolumn{2}{|c|}{ Total } & \multicolumn{2}{|c|}{ Never } & \multicolumn{2}{|c|}{ Rarely } & \multicolumn{2}{|c|}{ Sometimes } & \multicolumn{2}{|c|}{ Often } & \multirow[b]{2}{*}{$p$-Value * } \\
\hline & $N$ & $\%$ & $n$ & $\%$ & $n$ & $\%$ & $n$ & $\%$ & $n$ & $\%$ & \\
\hline$N$ & 791 & 100.0 & 165 & 20.9 & 225 & 28.4 & 261 & 33.0 & 140 & 17.7 & \\
\hline \multicolumn{12}{|l|}{ Area } \\
\hline Rural & 260 & 32.9 & 32 & 19.4 & 71 & 31.6 & 94 & 36.0 & 63 & 45.0 & \multirow{3}{*}{$<0.001$} \\
\hline Suburban & 263 & 33.2 & 52 & 31.5 & 81 & 36.0 & 92 & 35.2 & 38 & 27.1 & \\
\hline Urban & 268 & 33.9 & 81 & 49.1 & 73 & 32.4 & 75 & 28.7 & 39 & 27.9 & \\
\hline \multicolumn{12}{|l|}{ Sex } \\
\hline Women & 435 & 55.0 & 81 & 49.1 & 126 & 56.0 & 144 & 55.2 & 84 & 60.0 & \multirow[t]{2}{*}{0.280} \\
\hline Men & 356 & 45.0 & 84 & 50.9 & 99 & 44.0 & 117 & 44.8 & 56 & 40.0 & \\
\hline Age & & & & & & & & & & 0.0 & \\
\hline$<60$ & 473 & 59.8 & 100 & 60.6 & 120 & 53.3 & 147 & 56.3 & 106 & 75.7 & $<0.001$ \\
\hline$\geq 60$ & 318 & 40.2 & 65 & 39.4 & 105 & 46.7 & 114 & 43.7 & 34 & 24.3 & \\
\hline \multicolumn{12}{|l|}{ Family structure } \\
\hline Living alone & 99 & 12.5 & 39 & 23.6 & 25 & 11.1 & 23 & 8.8 & 12 & 8.6 & \multirow[t]{2}{*}{$<0.001$} \\
\hline Living 2 or more members & 692 & 87.5 & 126 & 76.4 & 200 & 88.9 & 238 & 91.2 & 128 & 91.4 & \\
\hline \multicolumn{12}{|l|}{ Educational background } \\
\hline$\leq$ High school & 353 & 44.6 & 68 & 41.2 & 107 & 47.6 & 131 & 50.2 & 47 & 33.6 & \multirow[t]{2}{*}{0.008} \\
\hline >High school & 438 & 55.4 & 97 & 58.8 & 118 & 52.4 & 130 & 49.8 & 93 & 66.4 & \\
\hline \multicolumn{12}{|l|}{ Employment status } \\
\hline Unemployed/retired & 258 & 32.6 & 62 & 37.6 & 84 & 37.3 & 88 & 33.7 & 24 & 17.1 & \multirow[t]{2}{*}{0.271} \\
\hline Employed & 533 & 67.4 & 103 & 62.4 & 141 & 62.7 & 173 & 66.3 & 116 & 82.9 & \\
\hline \multicolumn{12}{|l|}{ Economic circumstances } \\
\hline Poor & 178 & 22.5 & 43 & 26.1 & 36 & 16.0 & 67 & 25.7 & 32 & 22.9 & \multirow{3}{*}{0.093} \\
\hline Fair & 280 & 35.4 & 52 & 31.5 & 82 & 36.4 & 98 & 37.5 & 48 & 34.3 & \\
\hline Good & 333 & 42.1 & 70 & 42.4 & 107 & 47.6 & 96 & 36.8 & 60 & 42.9 & \\
\hline \multicolumn{12}{|l|}{ Health Attitude } \\
\hline Low & 235 & 29.7 & 50 & 30.3 & 61 & 27.1 & 71 & 27.2 & 53 & 37.9 & \multirow[t]{2}{*}{0.112} \\
\hline High & 556 & 70.3 & 115 & 69.7 & 164 & 72.9 & 190 & 72.8 & 87 & 62.1 & \\
\hline \multicolumn{12}{|c|}{ Subjective difficulty in food-store access } \\
\hline Difficult & 219 & 27.7 & 43 & 26.1 & 57 & 25.3 & 71 & 27.2 & 48 & 34.3 & \multirow[t]{2}{*}{0.271} \\
\hline Easy & 572 & 72.3 & 122 & 73.9 & 168 & 74.7 & 190 & 72.8 & 92 & 65.7 & \\
\hline \multicolumn{12}{|l|}{ Vegetable growing } \\
\hline Non-grower & 394 & 49.8 & 96 & 58.2 & 110 & 48.9 & 121 & 46.4 & 67 & 47.9 & 0057 \\
\hline Gardener & 290 & 36.7 & 47 & 28.5 & 77 & 34.2 & 111 & 42.5 & 55 & 39.3 & 0.057 \\
\hline Farmer & 107 & 13.5 & 22 & 13.3 & 38 & 16.9 & 29 & 11.1 & 18 & 12.9 & \\
\hline & Mean & SD & Mean & $\mathrm{SD}$ & Mean & SD & Mean & SD & Mean & SD & \\
\hline Social cohesion (4-20) & 13.2 & 3.0 & 12.4 & 3.1 & 13.1 & 2.9 & 13.3 & 3.0 & 14.3 & 2.9 & $<0.001$ \\
\hline
\end{tabular}

* One-way ANOVA for social cohesion, and chi-square test for all the other valuables. SD: standard deviation. 
Table A3. Participants' characteristics according to vegetable receiving frequency among non-gardeners (Survey 2).

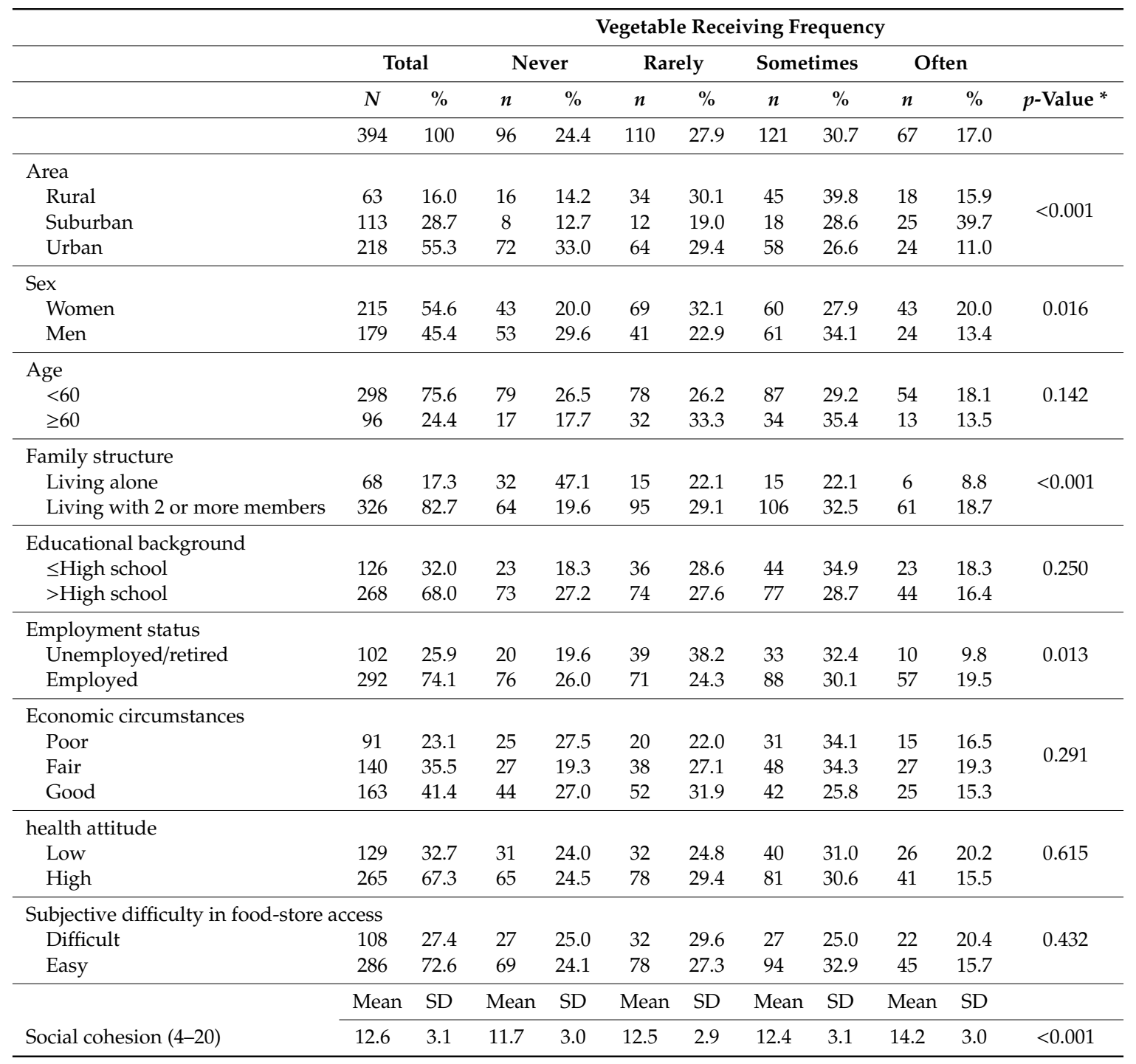

* One-way ANOVA for social cohesion, and chi-square test for other valuables. SD: standard deviation.

\section{References}

1. Forssell, S.; Lankoski, L. The sustainability promise of alternative food networks: An examination through "alternative" characteristics. Agric. Hum. Values 2015, 32, 63. [CrossRef]

2. Michel-Villarreal, R.; Hingley, M.; Canavari, M.; Bregoli, I. Sustainability in Alternative Food Networks: A Systematic Literature Review. Sustainability 2019, 11, 859. [CrossRef]

3. Kamiyama, C.; Hashimoto, S.; Kohsaka, R.; Saito, O. Non-Market food provisioning services via homegardens and communal sharing in Satoyama Socio-Ecological production landscapes on Japan's Noto peninsula. Ecosyst. Serv. 2016, 17, 185-196. [CrossRef]

4. Kamiyama, C.; Nakazawa, N.; Saito, O. Measuring nonmarket food provisioning services through Self-Production and social networks in Japan. J. Jpn. Soc. Civ. Eng. Ser. G (Environ. Res.) 2014, 70, 361-369.

5. Tatebayashi, K.; Kamiyama, C.; Matsui, T.; Saito, O.; Machimura, T. Accounting shadow benefits of Non-Market food through Food-Sharing networks on Hachijo Island, Japan. Sustain. Sci. 2019, 14, 1-18. [CrossRef] 
6. Saito, O.; Havas, J.; Shirai, K.; Kurisu, K.; Aramaki, T.; Hanaki, K. Non-Market food provisioning services in Hachijo Island, Japan and their implications toward building a resilient island. J. Jpn. Soc. Civ. Eng. Ser. G (Environ. Res.) 2015, 71, 349-357.

7. Saito, O.; Kamiyama, C.; Hashimoto, S. Non-Market food provision and sharing in Japan's Socio-Ecological production landscapes. Sustainability 2018, 10, 213. [CrossRef]

8. Machida, D.; Yoshida, T. Relationship between Vegetable Intake and Homegrown Vegetable Growing/Intake among Adults in Developed Countries: A Systematic Review. Jpn. J. Nutr. Diet. 2015, 73, 62-68. [CrossRef]

9. Garcia, M.T.; Ribeiro, S.M.; Germani, A.C.C.G.; Bógus, C.M. The impact of urban gardens on adequate and healthy food: A systematic review. Public Health Nutr. 2018, 21, 416-425. [CrossRef]

10. Alaimo, K.; Beavers, A.W.; Crawford, C.; Snyder, E.H.; Litt, J.S. Amplifying health through community gardens: A framework for advancing multicomponent, behaviorally based neighborhood interventions. Curr. Environ. Health Rep. 2016, 3, 302-312. [CrossRef]

11. McCormack, L.A.; Laska, M.N.; Larson, N.I.; Story, M. Review of the nutritional implications of farmers' markets and community gardens: A call for evaluation and research efforts. J. Am. Diet. Assoc. 2010, 110, 399-408. [CrossRef] [PubMed]

12. Morawicki, R.O.; Díaz, G.D.J. Food sustainability in the context of human behavior. Yale J. Biol. Med. 2018, 91, 191-196. [PubMed]

13. Al-Delaimy, W.K.; Webb, M. Community gardens as environmental health interventions: Benefits versus potential risks. Curr. Environ. Health Rep. 2017, 4, 252-265. [CrossRef] [PubMed]

14. United Nations. Goal 2: Zero Hunger. Available online: https://www.un.org/sustainabledevelopment/ hunger/ (accessed on 16 April 2019).

15. Zhan, J.; Liu, Y.J.; Cai, L.B.; Xu, F.R.; Xie, T.; He, Q.Q. Fruit and vegetable consumption and risk of cardiovascular disease: A Meta-Analysis of prospective cohort studies. Crit. Rev. Food Sci. Nutr. 2017, 57, 1650-1663. [CrossRef] [PubMed]

16. Wang, X.; Ouyang, Y.; Liu, J.; Zhu, M.; Zhao, G.; Bao, W.; Hu, F.B. Fruit and vegetable consumption and mortality from all causes, cardiovascular disease, and cancer: Systematic review and Dose-Response meta-analysis of prospective cohort studies. BMJ 2014, 29, 349. [CrossRef]

17. Machida, D.; Yoshida, T. Negative association of vegetable cultivation with the proportion of severely insufficient vegetable intake both directly and indirectly: A Cross-Sectional study in a city in Gunma, Japan. J. Rural Med. 2018, 13, 160-167. [CrossRef]

18. Machida, D.; Yoshida, T. The influence of vegetable growing, receiving, and buying in farmers' markets on the frequency of vegetable intake: Focusing on residents of mountainous rural areas with limited food access and flourished vegetable growing. J. Rural Plan. 2018, 37, 43-50. [CrossRef]

19. Umezawa, A.; Miwa, T.; Shibui, E.; Namikawa, T.; Tanaka, N.; Ishikawa, N. Total vegetable intake and homegrown vegetable intake in the rural area residents of Hokkaido. Jpn. J. Nutr. Diet. 2012, 70, 283-293. [CrossRef]

20. Soga, M.; Cox, D.T.; Yamaura, Y.; Gaston, J.K.; Kurisu, K.; Hanaki, K. Health benefits of urban allotment gardening: Improved physical and psychological well-being and social integration. Int. J. Environ. Res. Public Health 2017, 14, 71. [CrossRef]

21. Machida, D.; Yoshida, T. Relationship between fruit and vegetable gardening and health-related factors: Male community gardeners aged 50-74 years living in a suburban area of Japan. Jpn. J. Public Health 2017, 64, 684-694.

22. Machida, D.; Onoe, H.; Yoshida, T. The relationship between vegetable cultivation and consumption among participants of food and nutrition classes in Gunma Prefecture. J. Jpn. Soc. Shokuiku 2012, 10, 109-114.

23. Draper, C.; Freedman, D. Review and analysis of the benefits, purposes, and motivations associated with community gardening in the United States. J. Community Pract. 2010, 18, 458-492. [CrossRef]

24. Yuzawa, A. A study on user characteristics and effect of allotment garden. J. Archit. Plan. 2012, 77, 1095-1102. [CrossRef]

25. Aizaki, H.; Onimaru, T.; Kayama, D.; Ishida, K. Non-farmers' preference for assisting with farm tasks as a method of health promotion. Jpn. Agric. Res. Q. 2016, 50, 135-142. [CrossRef]

26. International Union for Health Promotion and Education. IUHPE Position Paper: Advancing Health Promoting Food Systems. 2015. Available online: https://www.iuhpe.org/images/IUHPE/officialstatements/ IUHPE_Food_Systems_Position_Paper.pdf (accessed on 16 April 2019). 
27. Machida, D.; Yoshida, T. Vegetable intake frequency is higher among the rural than among the urban or suburban residents, and is partially related to vegetable cultivation, receiving, and purchasing at farmers' markets: A Cross-Sectional study in a city within Gunma, Japan. J. Rural Med. 2018, 13, 116-123. [CrossRef] [PubMed]

28. Litt, J.S.; Soobader, M.J.; Turbin, M.S.; Hale, J.W.; Buchenau, M.; Marshall, J.A. The influence of social involvement, neighborhood aesthetics, and community garden participation on fruit and vegetable consumption. Am. J. Public Health 2011, 101, 1466-1473. [CrossRef] [PubMed]

29. Litt, J.S.; Schmiege, S.J.; Hale, J.W. Exploring ecological, emotional and social levers of self-rated health for urban gardeners and non-gardeners: A path analysis. Soc. Sci. Med. 2015, 144, 1-8. [CrossRef]

30. Yoshiba, K.; Takemi, Y.; Ishikawa, M.; Yokoyama, T.; Nakaya, T.; Murayama, N. Relationship between dietary diversity and food access among elderly living alone in Saitama Prefecture. Jpn. J. Public Health 2015, 62, 707-718.

31. Mujahid, M.S.; Diez Roux, A.; Morenoff, J.D.; Raghunathan, T. Assessing the measurement properties of neighborhood scales: From psychometrics to ecometrics. Am. J. Epidemiol. 2007, 165, 858-867. [CrossRef]

32. Oga, H.; Omori, T.; Kondo, T.; Oyama, O. Study on validity of social capital scale by District-Development of "The neighborhood scales Japanese version" from ecometric point. J. Health Welf. Stat. 2010, 57, 32-39.

33. Japanese Ministry of Agriculture, Forestry and Fisheries. About the Agricultural Area Classification System. Available online: http://www.maff.go.jp/j/tokei/chiiki_ruikei/setsumei.html (accessed on 16 April 2019). (In Japanese)

34. Hayashi, F.; Takemi, Y.; Murayama, N. The Association between Economic Status and Diet-Related Attitudes and Behaviors, as Well as Diet-related Quality of Life in Adults. Jpn. J. Nutr. Diet. 2015, 73, 51-61. [CrossRef]

35. Oba, R.; Hirano, T.; Kurihara, S. Graphical causal structure analysis of consumers' preference to local foods. J. Rural Plan. Assoc. 2006, 25, 413-418. [CrossRef]

36. Greer, A.E.; Davis, S.; Sandolo, C.; Gaudet, N.; Castrogivanni, B. Agricultural experiences are positively associated with high school students' fruit and vegetable perceptions and consumption. J. Nutr. Educ. Behav. 2018, 50, 133-140. [CrossRef] [PubMed]

37. Tey, Y.S.; Arsil, P.; Brindal, M.; Teoh, C.T.; Lim, H.W. Motivations underlying consumers' preference for farmers markets in Klang Valley: A Means-End chain approach. Sustainability 2017, 9, 1958. [CrossRef]

38. Menapace, L.; Raffaelli, R. Preferences for locally grown products: Evidence from a natural field experiment. Eur. Rev. Agric. Econ. 2017, 44, 255-284. [CrossRef]

39. Japanese Ministry of Agriculture, Forestry and Fisheries. Statistics on the Agricultural Labor Force. Available online: http://www.maff.go.jp/j/tokei/sihyo/data/08.html (accessed on 16 April 2019). (In Japanese)

40. Japanese Ministry of Agriculture, Forestry and Fisheries. Area Survey. Available online: http://www.maff.go. jp/j/tokei/kouhyou/sakumotu/menseki/index.html\#r (accessed on 16 April 2019). (In Japanese)

41. Japanese Ministry of Agriculture, Forestry and Fisheries. Population Decline in Rural Areas. Available online: http://www.maff.go.jp/j/wpaper/w_maff/h26/h26_h/trend/part1/chap0/c0_1_01.html (accessed on 16 April 2019). (In Japanese)

(C) 2019 by the authors. Licensee MDPI, Basel, Switzerland. This article is an open access article distributed under the terms and conditions of the Creative Commons Attribution (CC BY) license (http://creativecommons.org/licenses/by/4.0/). 